\section{TRACHEOTOMY IN CROUP.}

\author{
By C. E. PRIOR, M.D., Bedford.
}

Ime following case may not be uninteresting, as indicating with some exactitude the condition under which a favourable result may be hoped for from the operation of tracheotomy in this formidable disease.

A. B., a little boy, aged 5 years, has, according to his mother's statement (one not, however, much to be relied upon), suffered from an early age from a certain degree of roughness of voice and occasional harshness of breathing, and has on more than one occasion had croupy paroxysms of some sererity. When first brought under my own notice, in the early part of Septcmber last, there were few words which he could pronounce out of a harsh whisper; but I do not remember to have observed any difficulty of breathing. Towards the end of that month, my attention was more immediately drawn to him on account of a return of croupy symptoms, which continued for some days, generally with exacerbation towards the evening and night, passing off somewhat in the mornings, and accompanied with bronchitis and considerable secretion of nucus.

From the somewhat chronic nature of the symptoms, rigid depletion did not appear to be indicated, and they were combated by confinernent to a warm atmosphere, the employment of calomel with antimonials, the occasional use of emetics, and latterly of a warm bath, with the application of a blister to the sternum. Under the use of these remedies, the case fluctuated for some days; the breathing being occasionally much relieved, at other times considerably oppressed.

Un visiting him on the morning of Friday, October 5th, the case had assumed a very much more formidable aspect, the croupy breathing had coutinued unrelieved through the night, emetics and the warm bath had bcen resorted to in vain, the pulse was fteble and fluctuating, the lips blue, the circulation of the extremities impeded, and the symptoms of asphyxia were imminent. Some leeches which I had left, with directions for their use in case of necessity, had not been employed; and running over the circumstances rapidly in my mind, the operation of tracheotomy appeared to me to afford the only resource; the character of the bronchial secretion up to a recent date induced me to hope that false membrane did not extend low down the trachea ; while the previous state of the child, and rudeness of the voice, pointed rather to the existence of inflammatory obstruction towards the upper part of the tube and lower portion of the larynx.

The operation was accordingly performed within half an hour; the difficulties experienced being of the usual character from the limited space at command, and the depth at which the trachea is situated, as well as from its troublesome and constant motion, and its rolling under the point of the knife; venous hxmorrhage was trifling, and irritation of the trachea from regurgitation was avoided as wuch as possible by completely inverting the body with the neck a little extended on the commencement of each paroxysm of coughing. As it was, life had almost ebbed away before the operation was completed; nor, singularly enough, was the relief experienced so great and immediate as I have seen in cases which have nevertheles; resulted unfavourably; but there was a gradual and steady amendment. At the end of a week, the silver tube was removed; within three weeks the wound was completely healed; and at the preseut date the boy is in very good health, but has still some little harshness of breathing and deficiency of voice, which, should he remain under my eye, I shall endeavour to combat by the use of small "flying blisters" to the anterior portion of the larynx, and the occasional emplopment of mercurials.

As a dernier ressort in croup, tracheotomy has been tested on a large scale, both in this country and in the continental hospitals, and the results are conclusively against its adoption; the downward extension of false membrane is generally so considerable as to baffle all our efforts to obtain a free parage; and, indopendently of this, and notrithstanding the most flattering appearances of relief, the nerrous system of the child will generally succumb in most disappointing and distressing manner; but, nevertheless, cases are occasionally-rarely, no doubt-to be met vith, such as the above, in which the probable limitation of the disease, at all events of the formation of false membrane, to the upper part of the trachea or lower portion of the larynx, gives a fair hope of a successful result from the operation.

While on the subject, I may as well mention that another case has recently occurred to me in which I can conceive a successful result to have been possible from this operation.

My patient, aged 8 years, having enormously enlarged tousils, and breathing with some difficulty on the slightest cold, was attacked with scarlatina anginosa in its most severe form. Symptoms of asphyxia began to show themselves; and I was in the act of applying leeches to the throat, and just suggesting tracheotomy to the relatives as the only resource, should the leeches be unsuccessful, when he was seized with convulsions, and expired in a few moments. Had there been time, the operation would, I think, have been fully justified; nor could its execution have exercised an unfavourable influence on the primary disease.

\section{BIBIIOGRAPHICAT NOTICES.}

Commentaries on the Surgery of the War. By G. J. Gothrie, F.R.S. London: Henry Renshar.

Ir is the fashion, and perhaps, in the main, a just one, to say that the Peninsular men are worn out, and incapable of taking part in the great fight now waging in the East. Any rule, however, must have its exceptions; and Mr. Guthrie, the able surgeon, who gathered his great experience in that grand panorama of general actions, sieges, and skirmishes, which followed each other, with little intermission, from the battle of Rolica, in 1808, to that of Waterloo, in 1815, is one of them. Indeed, the vigour of this old man strikes us as something remarkable. Not content with posting up his great work on military surgery to the latest moment-not content with gathering all the experience he possibly could from the camp before Sebastopol, as late as the latter end of September, he still leaves his pages open, and promises us further addenda in a future issue of his work. Mr. Guthrie has not contented himself merely with collecting the experience of others in the distant battle-field, which his age would not permit him to visit in person; he has suggested numerous operations, some of which have turned out very successful; thus his mind, acting upon younger cerebrums, has been actively employed in the camp. The depressing influences which have been so long at work in the Crimea appear to have rendered deadly all the great operations in the upper portion of the lower extremity. Not one case of amputation at the hip-joint ever recovered. Dr. Lyous, pathologist to the army in the East, in a letter to the author, describing the post mortem appearance of the soft parts of a soldier who had been shot through the thigh, makes the following remarkable statement: "Beneath the integuments all the muscular and other textures, from the seat of injury to the groin, were converted into a soft, broken down, black, rotten mass; and I may here observe that this low, but intense disorganising process, extending through a greater part of the limb, has presented itself in several of iny examinations of somewhat similar injuries, and appears to me to be connected with a peculiar pathological state in which all the vilal organs remain sound, but the vis vita is remarkably reduced below par." How can we then wonder that the red of the surgeon is powerless, when uature, instead of desiring to heal, seems predisposed to destroy. The wickedness of subjecting the soldier to unnecessary hardship is 